\title{
Catecholaminergic Polymorphic Ventricular Tachycardia Type 1
}

National Cancer Institute

\section{Source}

National Cancer Institute. Catecholaminergic Polymorphic Ventricular Tachycardia Type

1. NCl Thesaurus. Code C123414.

Polymorphic ventricular tachycardia induced by adrenergic stress. It is inherited in an autosomal dominant pattern and is caused by mutations in the ryanodine receptor 2 (RYR2) gene. 